\title{
A Details study on: Developing Biodegradable Plastics from Potato starch with enhanced physico- mechanical properties
}

\section{Farhana Momotaz}

lowa State University

Naimul Hasan ( $\square$ naimul4105@gmail.com )

Khulna University of Engineering and Technology https://orcid.org/0000-0002-3463-7726

Aniruddha Sarkar

Khulna University of Engineering and Technology

\section{Research Article}

Keywords: Potato Starch, Plastics, Biodegradability, physico-mechanical properties, competitive study

Posted Date: February 1st, 2022

DOI: https://doi.org/10.21203/rs.3.rs-1240157/v1

License: (c) (i) This work is licensed under a Creative Commons Attribution 4.0 International License.

Read Full License 


\title{
A Details study on: Developing Biodegradable Plastics from Potato starch with enhanced physico-mechanical properties
}

\begin{abstract}
Plastic is very much indestructible even after a long period of time in the environment as it is mainly a derivative of strongly bonded long-chain petrochemical-based materials. Nowadays, plastic wastes have become an environmental hazard. However, a Starch based bio plastic can be a solution of this problem. Starch is a natural biopolymer having mainly two types of polymer glucose. In this research work, a biodegradable plastic is developed form potato starch. The advantages of starch-based plastic are its abundance and low cost. However, most of the starch-based materials exhibit very poor physico-mechanical properties like low tensiletear strength, high stiffness, elongation at break and poor moisture stability. Improvement of starch-based bioplastic properties is being attempted through starch modification, reinforcements (both organic and inorganic), processing conditions, and use of compatibilizers to develop substitutes for conventional plastics. The physicmechanical properties of the biodegradable plastic have been ameliorated through some well designed processes. Several tests have been conducted on the biodegradable plastic as well as on the regular plastic in order to make a comparative study between them. Test results showed a very promising start for the biodegradable plastic for becoming the alternative of regular non-biodegradable plastics.
\end{abstract}

Keywords: Potato Starch; Plastics; Biodegradability; physico-mechanical properties; competitive study

\subsection{INTRODUCTION}

The ingenuity behind inventing plastic was considered as a ground breaking innovation when it first came into widespread use in general goods and jewelry in 1920s. The diversity and adaptability of plastic has made it as a day to day life product in almost all over the glove. However, plastic is mainly a petrochemical-based materials which is a non-biodegradable product. So it has raised environmental concerns and hence, the driving force in the search for 'green' alternatives for which starch remains the front liner. Starting from the morning till going to the bed, plastic is almost everywhere due to its universal use in almost every products that are generally used in a day to day life. Since the innovation of plastic, it is estimated that around 8 billion tons of plastic has been produced all over the world in order to cope up with ever growing demand of plastic products [1]. Plastic is mainly a derivative of long chain petrochemical-based materials which is very much indestructible even after a long period of time in the environment. Plastic materials are consisted of a wide range of synthetic or semisynthetic organic compounds with very high molecular mass which are malleable and can be molded into solid objects [2]. Due to the low production cost and easy manufacturing process of plastic materials, it is very much impossible to create an absolute alternative of plastic materials. The main building block of plastic polymers is the Hydro-Carbon monomers. Carbon atoms exist at the main chain of high molecular long chain polymer and Hydrogen atoms are present in the side chain of the polymers. Carbon-Carbon bonds Carbon-Hydrogen bonds are very much strong in nature which makes the polymers resistive of the environmental facts [3]. Plastics have various uses staring from the product packing to the medical uses and so on. Different types of plastics are produced now a day in order to fulfill different purposes such as, polyethylene are used for the packaging and 
polyvinyl chloride are used for the making construction materials and pipes due to its higher strength. However the non-biodegradability property of these plastic materials is creating a great environmental threat for all the living being of this planet [4]. Most of the manufactured plastics are getting dumped into the sea which is then consumed by sea creatures and thus entering in our food chain. This uprising problem drives the innovators to find the green alterative of plastic materials where starch based products remains as front liner. Starch is one kind of natural biopolymer which has mainly two polymer types of glucose namely amylose and amylopectin [5]. Starch is mainly a white, soft, tasteless powder like substance which is insoluble in organic and inorganic solvents. The general formula for starch molecule is $\left(\mathrm{C}_{6} \mathrm{H}_{10} \mathrm{O}_{5}\right)_{\mathrm{n}}$. Glucose monomers are connected with each other in $\alpha$ 1,4 glycoside bond [6]. Like the plastic materials, starch also has long chain polymers as well. The structure of a plastic (polyethylene) and starch can be seen from the figure 1. Here it can be clearly seen in figure 1(a) that polyethylene has a long chain of polymers consisted with ethylene monomers as the repeating unit. In case of starch, glucose is the repeating unit and they are connected with each other using the $\alpha 1,4$ glycoside bonds which can be seen in the figure 1(b) as well.

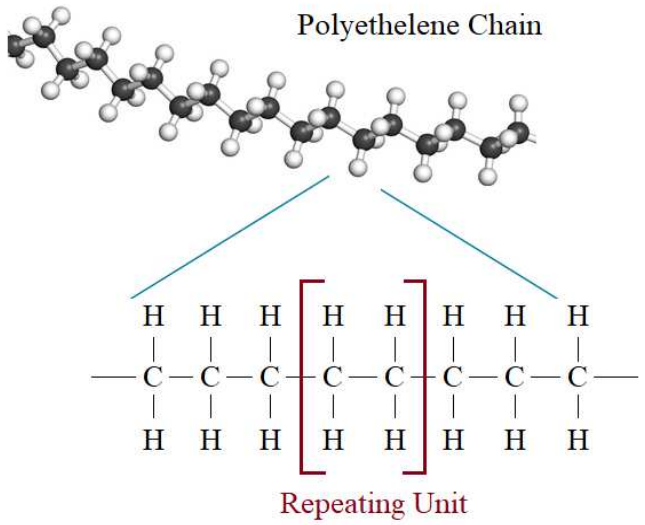

(a)

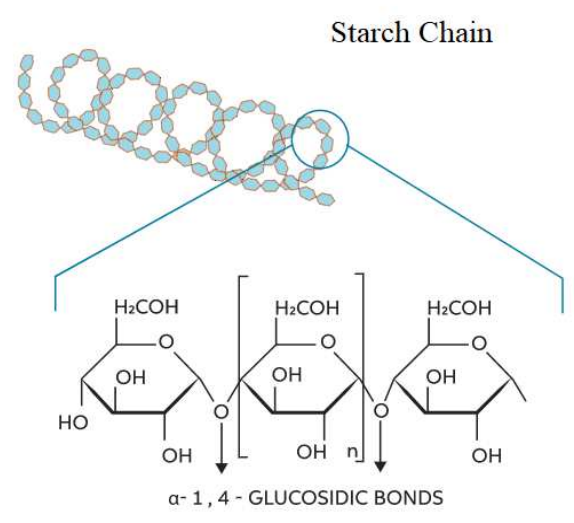

(b)

Figure 1: Structure of (a) polyethylene chain (b) Starch chain polymer

The main advantages of starch-based biodegradable plastic are its abundance of raw materials and easy manufacturing process with low cost. During the photosynthesis process, starch is produced in the plants as the reserve food supply [7]. Starch can stored in different organ of plants such as in the root of cassava plant, the stem pith of sago, the tuber of the potato and the seeds of corn, rice and wheat. This starch can be collected by crushing or grinding the tubers or seeds and then mixing up with the water in order to collect the starch as the sediment. This organic starch then can be used in order to make the biodegradable plastics by going through various complicated processes [8]. However, most of the starch based plastics show very poor physical properties such as tensile strength, stiffness and elongation at break and poor moisture stability, which are not suitable for being used as the replacement of plastic products [9]. It is important to enhance the physical and mechanical properties of starch based plastic in order to use them as the alternative of plastics. In this project work the main focus is to develop the manufacturing process of starch based biodegradable plastic with optimal physical and mechanical properties. Improvement of the properties of the starch-based bio-composites is being 
attempted through starch modification, reinforcements (both organic and inorganic), processing conditions and use of compatibilizers to develop substitutes for the conventional plastics.

As the sustainable source of starch which is the main raw material to produce biodegradable plastic, potato is the perfect competitor due to its huge cultivation all over the world. The starch extracting process from the potato is very conventional and easy process. Starch itself can create a film like martial which exhibits very poor mechanical properties [10]. To overcome that hurdle in this project we have added different organic and inorganic chemicals and auxiliaries with starch to enhance the physical and mechanical properties. We have done starch modification by blending starch with polyvinyl alcohol or PVA (polymerizing material) which helps the starch to build much stronger long chain polymer bond. The material Agar-agar is also used to modify the starch and it plays almost similar role as the PVA. In order to prevent the starch from getting affected by fungus or bacteria easy as it is an organic product; acetic acid is also used to prepare the biodegradable plastic [11]. Glycerin is used to control the moisture content in the biodegradable plastic [12]. However, distilled water is used to make the overall solution of starch and other chemical and auxiliaries. The main focus of this project is to find an optimal recipe for manufacturing biodegradable plastic with high-quality properties by working with different combination of the chemicals and auxiliaries. In order to create the biodegradable plastic different process like solution preparation according to different recipes, film formation, polymerization and curing process need to be done. In this research work worked with four different recipes and created four different biodegradable plastics. Among those biodegradable plastics one of them shows very promising physicmechanical properties. Further investigations are done on that particular biodegradable plastic to learn its behaviors.

Different physical testes like Tear strength, Tensile strength, Stiffness, GSM, Melting point, Water vapor transmission have been done of the specific biodegradable plastic to understand and inspect the physicmechanical properties [13]. As we are trying to find an alternative of regular plastic through this project, so it is important to make a comparison with regular plastics. We have taken a regular plastic with the same GSM as our biodegradable plastic and we have also completed all the physico-mechanical tests as before which are done to the biodegradable plastic. Test results are then compared with each other to understand how much compatible our new biodegradable plastic is against the regular plastic. In order to investigate the chemical composition of the biodegradable plastic Fourier-transform infrared spectroscopy (FTIR) test has been done of the produced material [14]. However, most importantly biodegradability test has been done to both the biodegradable plastic and regular non-biodegradable plastic to understand the biodegradable property of the plastic. In order to do the biodegradability test four different bacteria was collected and isolated from the soil sample. Then those bacteria have been cultivated and with the help of each bacteria cultivation the biodegradable plastic has been tested four different times to understand how much biodegradable the plastic is to each bacterium. Test results has to be further analyzed and compared with each other to have a better understand of the biodegradable plastic in comparison to the regular plastics [15].

Plastic is very much suitable for various purposes because of its strength, weather resistance, dimensional stability and chemical resistivity. So it is very difficult to find a perfect alternative of plastic materials. However it is important to find an alternative of the plastic material due to its non degradable properties. In this project work an effort is made to develop a biodegradable plastic form starch which is collected from potato. The new 
biodegradable plastic shows a very promising start with good physic-mechanical properties. However, a lot of development can be done to this biodegradable plastic and further study is needed to be done on this biodegradable plastic. The whole process of this research work is shown in a process flow chart which can be in figure 2. From the process flow chart it can be easily understood that the main process started depending on the potato in order to get the main raw material which is potato starch. After multiple processes and steps the final product came out in hand which then went through various physico-mechanical process for details study.

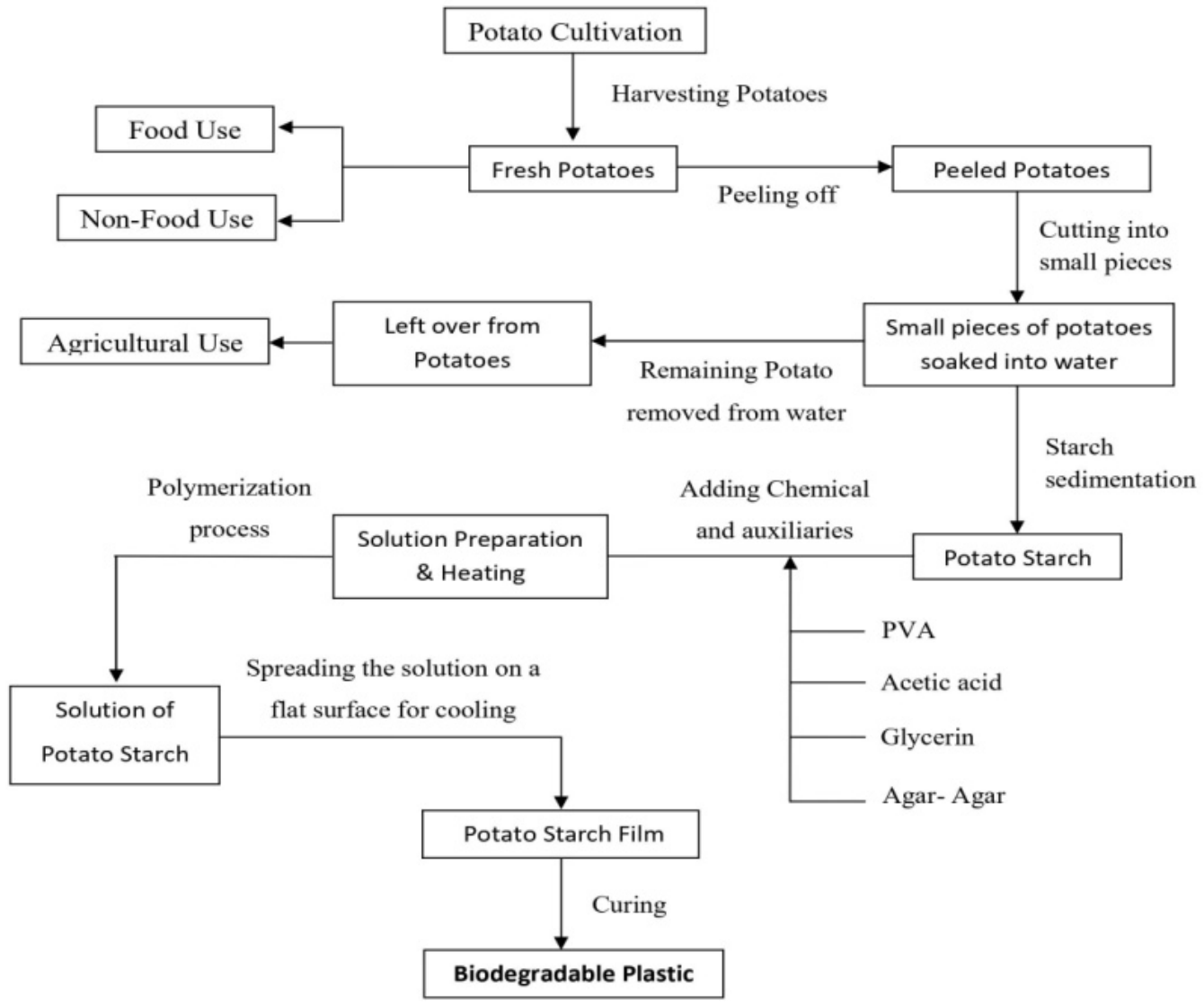

Figure 2: Process flow chart of potato-starch based biodegradable plastic preparation

\subsection{MATERIALS \& METHODE}

\subsection{Materials}

Tuber Potato ( $\underline{\text { Solanum tuberosum }}$ ) was purchased at Safe and Save market, Khulna, Bangladesh in order extract the potato starch from it. On average the size of the potato starch granules is $57.5 \mu \mathrm{m}$ and contents $18 \%$ of amylase. Distilled water was purchased from the Momotaj Chemical Ltd., Dhaka, Bangladesh. Polyvinyl alcohol or PVA $\left(\mathrm{M}_{\mathrm{w}}=44.05 \mathrm{~g} \cdot \mathrm{mol}^{-1}\right)\left[\mathrm{CH}_{2} \mathrm{CH}(\mathrm{OH})\right]_{\mathrm{n}}$ was purchased from Loba Chemie Pvt. Ltd., India. The PVA which bought was $87 \%$ hydrolyzed. Acetic Acid $\left(\mathrm{CH}_{3} \mathrm{COOH}\right)\left(\mathrm{M}_{\mathrm{w}}=60.052 \mathrm{~g} \cdot \mathrm{mol}^{-1}\right)$ was purchased from sigma-aldrich chemicals Pvt. Ltd., India. The Acetic acid was 0.8 Molar. Glycerin $\left(\mathrm{C}_{3} \mathrm{H}_{8} \mathrm{O}_{3}\right)\left(\mathrm{M}_{\mathrm{w}}=92.09382\right.$ $\mathrm{g} \cdot \mathrm{mol}^{-1}$ ) having the purity of $98 \%$, was supplied by Merck Chemicals, Darmstadt, Germany. Agar- agar $\left(\mathrm{C}_{14} \mathrm{H}_{24} \mathrm{O}_{9}\right)\left(\mathrm{M}_{\mathrm{w}}=336.33 \mathrm{~g} \cdot \mathrm{mol}^{-1}\right)$ was purchased from Momotaj Chemical Ltd., Dhaka, Bangladesh. 


\section{2 .2 Methodology}

\subsubsection{Starch Extraction}

Fresh potatoes were taken and cleaned thoroughly with the help of a scrubby brush in order to remove soils and dusts from the outside of the potatoes. Then the skin of the potatoes was peeled off using a peeling tool and any leftover eyes were also removed. After that a box grater was used to grate the potatoes by using hands. The grated potatoes were then taken into a pot and covered with warm water. Then a colander was placed onto another pot and a chess cloth was also lined with it. The grated potatoes were poured into it and they were bundled up in the chess cloth. After that the chess cloth was squeezed hard in order to get as much water out as possible. The left over grated potatoes were then again placed in a pot and covered with worm water and poured back into the chess cloth-lined colander. The chess cloth was again squeezed in order to drain more water. This process was repeated several times until the water ran mostly clean. Extracted water then needed to be settled for about 20 minutes and by this time the potato starch settled down at the bottom of the pot. The excess water then poured out of the pot and some fresh warm water was added into it. After around 20 minutes the excess water was again poured out from the pot and the starch was left to become dry hard. Then the dried starch was grinded with the help of a grinder to make powder starch.

\subsubsection{Plastic Preparation}

In order to find out the best combination for creating plastic form potato starch four different recipes were developed and tested out. All four recipes are given in the Table 1. The weight per liter ratio of Potato starch, PVA $\left[\mathrm{CH}_{2} \mathrm{CH}(\mathrm{OH})\right]_{n}$ and Agar-agar were at different combination in the four recipes. However, the weight per liter ratio of Acetic acid $(0.8 \mathrm{M})$ and glycerin were kept same for all the recipes. In case of plastic preparation, all of the ingredients were used according to each recipe.

Table 1: Different recipes for Biodegradable Plastic preparation

\begin{tabular}{lllll}
\hline Chemicals Used & Recipe 1 & Recipe 2 & Recipe 3 & Recipe 4 \\
\hline 1. Distilled water & $150 \mathrm{ml}$ & $150 \mathrm{ml}$ & $150 \mathrm{ml}$ & $150 \mathrm{ml}$ \\
2. Potato Starch & $20 \mathrm{gm} / \mathrm{L}$ & $20 \mathrm{gm} / \mathrm{L}$ & $40 \mathrm{gm} / \mathrm{L}$ & $40 \mathrm{gm} / \mathrm{L}$ \\
3. PVA & $6.4 \mathrm{gm} / \mathrm{L}$ & $6.4 \mathrm{gm} / \mathrm{L}$ & $12.8 \mathrm{gm} / \mathrm{L}$ & $25.6 \mathrm{gm} / \mathrm{L}$ \\
4. Acetic Acid(0.8M) & $8 \mathrm{ml} / \mathrm{L}$ & $8 \mathrm{ml} / \mathrm{L}$ & $8 \mathrm{ml} / \mathrm{L}$ & $8 \mathrm{ml} / \mathrm{L}$ \\
5. Glycerin & $8 \mathrm{ml} / \mathrm{L}$ & $8 \mathrm{ml} / \mathrm{L}$ & $8 \mathrm{ml} / \mathrm{L}$ & $8 \mathrm{ml} / \mathrm{L}$ \\
6.Agar agar & $12.8 \mathrm{gm} / \mathrm{L}$ & $25.6 \mathrm{gm} / \mathrm{L}$ & $0 \mathrm{gm} / \mathrm{L}$ & $0 \mathrm{gm} / \mathrm{L}$ \\
\hline
\end{tabular}

Necessary amount of water was taken according to each recipe into a biker. The biker was then placed on a hot plate magnetic stirrer. Temperature of the magnetic stirrer was not increased at the beginning, but the rpm of the magnetic stirrer was set at $200 \mathrm{rpm}$. First, the dry potato starch was added into the rotating water at room temperature according to each recipe. The potato starch was added gradually into the water so that it can easily get mixed into the water. Then the Acetic acid $(0.8 \mathrm{M})$ and Glycerin were added into the solution. After that the temperature and stirring revolution were gradually increased from $30^{\circ} \mathrm{C}$ to $150^{\circ} \mathrm{C}$ and 200 to $400 \mathrm{rpm}$. The temperature gradient was kept $1{ }^{\circ} \mathrm{C} /$ minute. While the temperature was increasing, Agar-agar was added 
into the solution at necessary amount according to the recipe. The temperature of the solution was constantly monitored with the help of a thermometer. When the temperature of the solution reached $150^{\circ} \mathrm{C}$, necessary amount of PVA was added very slowly, while the magnetic stirrer was still revolving. The mixing process was kept going for another 65 minutes while keeping the temperature constant at $150^{\circ} \mathrm{C}$. Appling high temperature was necessary to give the thermal stability to the biodegradable plastic. Gradually the thickness of the solution increased with the passage of time as the polymerization process took place in the solution. A colloid was formed which was poured out on glass plates as film. The films were air dried for 5 hours. Then the curing process was done to the film at $60^{\circ} \mathrm{C}$ for 30 minutes. After cooling; the polymer films were separated from glass plates and thus the biodegradable plastics were prepared. The all over process curve of Biodegradable Plastic preparation is shown in the figure 3.

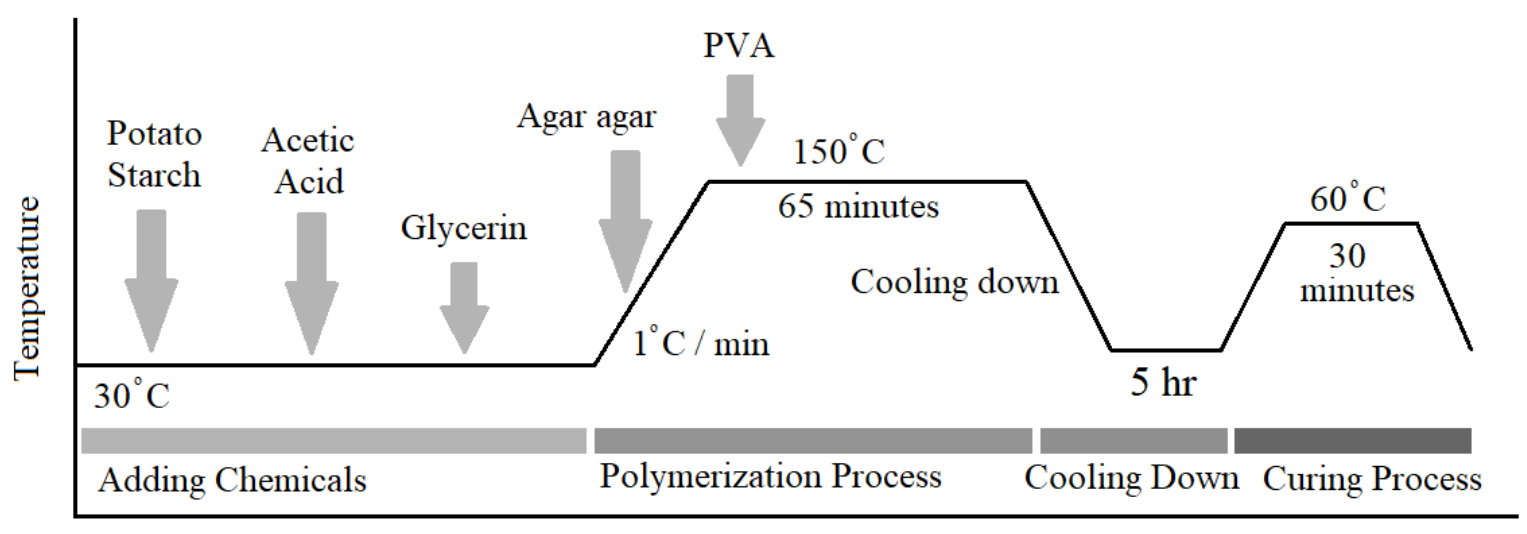

Time

Figure 3: Process curve of Biodegradable Plastic preparation

\subsection{Characterization}

Among the four different types of BP, all of them were not good enough to conduct further study. Many of them were very brittle in natural and did not have enough mechanical strength as per requirement. So with the help of primary speculations the sample which was made by using recipe 3 was selected for further physico-mechanical tests. All the testes were done in a controlled condition where the humidity was $65 \%$ and the temperature was $25^{\circ} \mathrm{C}$. In this research work, a comparative study has been made between the normal NBP and BP. So the GSM of the BP was determined and for the suppose of comparison, another NBP having almost similar GSM was taken. Almost all the physic-mechanical tests were done to both of the BP and NBP in order to have a clear comparison between them. The process of the each physico-mechanical tests are given below.

\subsubsection{Tensile strength}

Tensile strength test is one of the most common mechanical strength measurement systems while giving axial stretching force on the sample. This test is done to various materials including fabric, plastic, rubber, metals, paper, film etc. In the research work, the tensile test was done by using UTM (Universal Testing Machine). ASTM D638 testing method was used and the standard sample size for testing the tensile strength by using UTM machine was $100 \mathrm{~mm}$ in length and $75 \mathrm{~mm}$ in width. So $100 \times 75 \mathrm{~mm}$ samples were cut and attached with 
two tensile grips of the UTM machine. After that the testing process was started and the test speed was 75 $\mathrm{mm} / \mathrm{min}$. Whole test was controlled and monitored by using a computer and the test results were also shown in the computer by using a graphical representation. From the graph, different information like, force at pick , elongation at pick, elongation at break, strain at peak and strain at pick etc. can be found and they can indicate the mechanical strength of the tested material.

\subsubsection{Tear strength}

Tear strength test was done in order to measure how effectively a material can withstand the force after tearing. This test determines how much force is required to rupture a pre-slit material. It is very common for a plastic to get torn by an external force. However, it is important for the plastic to with stand even after being torn. Because if a plastic fails after a small tear and it cannot with stand any longer, then it would not likely to be used for general purposes. So, the tear strength of the biodegradable plastic needs to be much higher in order to use them regularly. In order to do the test, ASTM D1922 testing method was followed and the sample size was $210 \mathrm{~mm}$ in length and $50 \mathrm{~mm}$ in width. A $15 \mathrm{~mm}$ slit was made to each sample according to the testing method. 5 pound dead weigh was used in order to conduct the test using the ELMENDORF Tear Tester M005 model machine. Scaling system of the machine was used according to the amount of dead weight which was used during the test. Amount of tear strength of the samples were directly determined from the position of pointer on the scale.

\subsubsection{GSM Determination}

Gram per square meter or GSM is a very important parameter for determining the weight of a fixed amount of fabric or film like substance such as plastic, paper or cardboard etc. GSM indicates how bulky the material is relevant to the other materials. In the study GSM of biodegradable plastic was determined and according to the GSM of the biodegradable plastic, a normal non-biodegradable polyethylene was taken for the comparative study. GSM of the polyethylene was also determined in order to make sure the proper bulkiness of the polyethylene. GSM indicates the weight of a material have the area of $1 \mathrm{~m}^{2}$, but it is difficult to handle a $1 \mathrm{~m}^{2}$ sample. So in this study ASTM D3776 GSM testing method was followed and $100 \mathrm{~cm}^{2}$ samples were cut in a circle shape with the help of SCHRODER GSM cutter machine. The weight of the $100 \mathrm{~cm}^{2}$ samples were then determined using a Saffron Internal 4 Digit Analytical Balance. After that the GSM of the samples were determined using the following formula in the equation 1.

$$
G S M=\text { Weigth of } 100 \mathrm{~cm}^{2} \times 100
$$

\subsubsection{Stiffness Test}

Stiffness generally indicates the hardness and bendability of a material. Stiffness can be determined using both analog stiffness tester and pneumatic stiffness tester. In this experiment stiffness of biodegradable and nonbiodegradable plastic was measured using SUNDOO pneumatic stiffness tester according to ASTM D4032 testing standard. Length of the samples for testing the stiffness was kept at $204 \mathrm{~mm}$ and the width was $102 \mathrm{~mm}$ as per the testing method. Samples were placed on a 4-inch-square steel platform having an orifice of $38 \mathrm{~mm}$ diameter. A plunger of $25.4 \mathrm{~mm}$ diameter pushed the samples through the orifice for a distance of $57 \mathrm{~mm}$ in 1.7 second. The size of the plunger is smaller than the size of the orifice and it leaves 0.25 inch clearance around all the sides. The value of the force was shown in the screen of the pneumatic stiffness tester machine and the unit 
of the force was in Newton $(\mathrm{N})$. The maximum force which was needed in order to push the sample through the orifice was recorded as the stiffness value of the testing sample.

\subsubsection{Melting Point Determination}

Melting point is a very important parameter in case of plastics, because it indicates how much temperature a plastic can withstand before it melts down. There are various methods in order to determine the melting point of a material. Among them, capillary method is a very common one which is actually used in this study in order to manually determine the melting point of biodegradable and non-biodegradable plastic. In this method, a very little amount of testing sample was placed inside of a capillary and the capillary was then placed inside of STUART SMF30 melting point determining machine. The capillary was then heated up and it can be observed by using the eyepiece of the machine. The capillary was then gradually heated up inside of the machine and the sample was observed closely in order to see face transaction of the testing sample. Through the eyepiece, the capillary having the sample and the current temperature which was applied on the capillary could be seen. There was a small screen on the machine which also showed the current temperature of the sample. The temperature of the sample at the exact time when it turned into liquid from the solid state was noted down as the melting temperature or melting point of the sample plastic.

\subsubsection{Microscopic Examination}

Biodegradable plastic is a non-conductive material and due to this reason it is not suitable for Scanning Electron Microscopy (SEM) test. However it is important to observe the microscopic structure of the surface of the biodegradable plastic. So the microscopic structure of the biodegradable plastic was observed by using a XSP L101 Biological microscope. In order to conduct the test, a $15 \mathrm{~mm}^{2}$ sample was cut and placed carefully on a glass slide with the help of forceps. The specimen slide then placed and hold in a place on the mechanical stage directly under the objective lens with the help of slide-holder. The incoming light and the focus of the microscope were adjusted so that the specimen could be seen clearly through the eyepiece. There were different magnification levels in the microscope using different lenses. However, in this study 300X magnification was used to observe the surface of the biodegradable plastic. This magnification level was the most suitable for the experiment to observe and have better understanding about the surface of the biodegradable plastic.

\subsubsection{Fourier Transform Infrared (FTIR) Test}

Fourier Transform Infrared (FTIR) Spectroscopy is a very important test in order to find out the existing atoms and the different chemical bonds between then in the testing samples. This helps to have a better understand about the founding materials of that testing sample. In this test, spectroscopy method is used on various materials like organic, polymeric, and in some cases, inorganic materials to identify the substances which are present in those materials. In order to conduct the FTIR test, ASTM E168 testing method was followed. According to the testing method a $10 \mathrm{~mm}^{2}$ sample was cut into a square shape. The sample was then transferred with the help of forcipes on the sample plate of the SHIMADZU IRTracer-100 Fourier Transform Infrared Spectrophotometer. Then the Spectrophotometer examined the sample and generated a graph in the form of absorbance spectra, which showed the unique chemical bonds and the molecular structure of the testing 
samples. There were peaks at different positions of the graph which indicated the presence of different types of bonds, and thus different functional groups. Presences of expected materials in the samples were then confirmed by analyzing the spectrum graphs.

\subsubsection{Water Vapor Transmission Test}

Water vapor transmission test determines how much water vapor can be transmitted through the testing material under a fixed level of humidity and temperature. This property of the material indicates the amount of the passage of water vapor through the substance and the permeability for vapor barriers. This property is very important for various uses including the packaging and storing by using the material. In this study Water Vapor Transmission Tester WVTR-E96-M machine was used in order to measure the water vapor transmission rate of the both BP and NBP by following ASTM E96-M testing standard. A container pot made of Copper alloy was used for containing water as well as the testing sample. $100 \mathrm{ml}$ of water was taken into the pot and a $0.4 \mathrm{ft}^{2}$ sample was cut in a circular shape which was then attached inside of the pot using a ring shaped permeability cup. The weight of the pot including the ring shaped permeability cup was $150.734 \mathrm{gm}$. The total weight of the pot including the sample and $100 \mathrm{ml}$ was determined using an electric balance for better accuracy. Then the pot was put inside of the WVTR-E96-M machine and the machine was calibrated to $52 \%$ humidity and $32^{\circ} \mathrm{C}$ according to the test method. When the machine reached the predetermined humidity and temperature, the test started and ran for 30 minutes. After that the pot was taken out of the machine and the weight was the measured again as before. All these data were then used in order to determine the water vapor transmission rate of the sample by using the following formula in the equation 2 .

Water vapor transmission rate

$$
=\frac{\text { Total weight of the pot before test }(\mathrm{gm})-\text { Total weigth of the pot after test }(\mathrm{gm})}{\text { Time }(\text { hour }) \times \text { Area of the sample (square feet })}
$$

After calculating, the output value was the water vapor transmission rate of the testing sample and the unit was $\mathrm{gm} / \mathrm{hr} . \mathrm{ft}^{2}$. The water vapor transmission rate of both BP and NBP was determined using the same procedures.

\subsubsection{Biodegradability Test}

In order to conduct the biodegradable test we needed to isolate the bacteria from the soil as per in the previous research [16]. 100gm soil was taken into a water jar and mixed with 1 liter of water. Then the solution was done serial dilution to $10^{-9} \mathrm{M}$. That solution was used to conduct the biodegradable test of the normal plastic in order to find the intended bacteria which helped for the biodegradable test of our newly developed plastic. Mainly 4 types of bacteria were isolated and their separate colonies were developed in 4 different Petri dishes. They were leveled as bacteria PDB-1, PDB-2, PDB-3and PDB-4. Using the bacteria and supplemented minerals, each samples were placed into a conical flux for 10 days at $37^{\circ} \mathrm{C}$ inside the JSGI-150T machine. The samples were weighted before and after pulling them in the machine. From the weight difference of the samples, the biodegradability percentage was calculated for each sample by using the equation 3 .

$$
\text { Biodegradability percentage }=\frac{\text { Initial weigth }- \text { Final weigth }}{\text { Initial weigth }} * 100 \%
$$




\subsection{RESULT \& DISCUSSION}

\subsection{Tensile Strength}

The tensile strength curve from the UTM machine of both biodegradable and non-biodegradable plastic is shown in the Figure 4. It is a Force versus Elongation curve, where the Elongation is plotted in the $\mathrm{X}$ axis and the Force is plotted in the $\mathrm{Y}$ axis. Figure 4 (a) shows the tensile strength curve of the biodegradable plastic where Figure 4 (b) shows the tensile strength curve of the non-biodegradable plastic or regular polyethylene. Form the graph it can be seen that the Force at peak for biodegradable plastic is $153.35 \mathrm{~N}$ and the Force at peak for non-biodegradable plastic is $144.44 \mathrm{~N}$. So it clear indicates that the biodegradable plastic can withstand more pressure than the non-biodegradable plastic. It is important for the BP to withstand more pressure than the NBP. Because this BP is supposed to be used as a regular product and it will have to face stretch more often. Elongation at peak for the BP is $46.221 \mathrm{~mm}$, where Elongation at peak for NBP is only $10.085 \mathrm{~mm}$. This results show that the BP can stretch more before breaking than the NBP. So the BP will be able to withstand more pressure than the NBP before breaking. However, NBP has $142.124 \mathrm{~mm}$ elongation at break and BP has 54.175 $\mathrm{mm}$ elongation at break. This indicates that the NBP can elongate more than the BP after breaking. So the NBP has more elasticity than the BP. Strain percentage at peak of the BP and the NBP are $23.111 \%$ and $5.043 \%$ respectively. It clearly indicates that the BP can tolerate more strain than the NBP. So overall the tensile strength curves of BP and NBP indicate that the BP is much stronger than the NBP and it can withstand more stretch than the regular NBP. This makes the BP suitable for regular use as like the NBP. However, the elasticity of the $\mathrm{BP}$ is less than the NBP and there is good scope to work on it in order to make the BP more elastic.

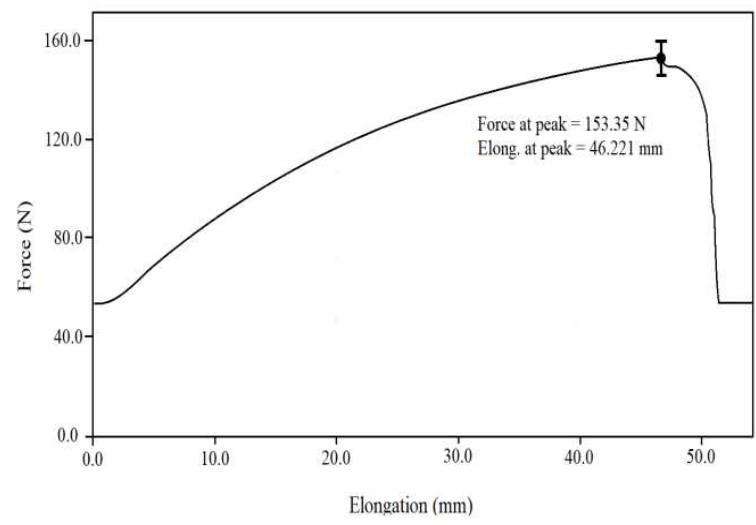

(a)

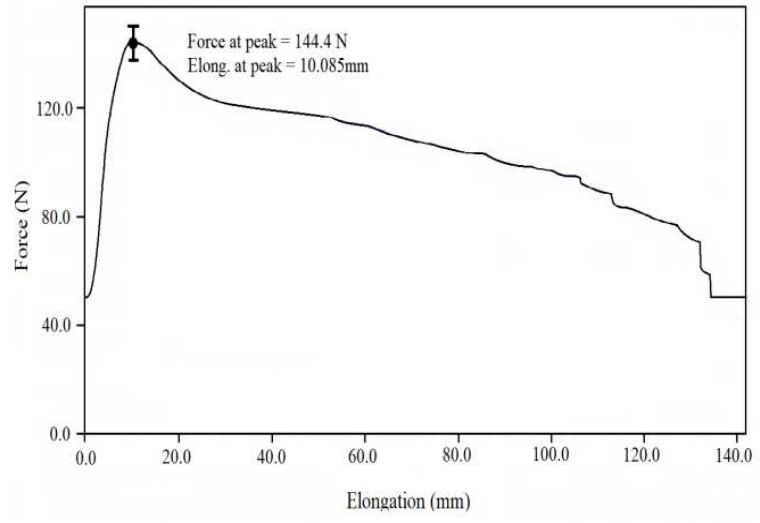

(b)

Figure 4: Tensile strength test curve for (a) BP \& (b) NBP

Tear strength tests of the BP and NBP were done using the 5lb. dead weight in the ELMENDORF Tear Tester M005 model machine. So the outer most scale of the machine was used as per the dead weight. The tear strength of the BP was determined $57.5 \mathrm{~N}$, where the tear strength of the NBP was determined 46.5 N. So it means, 57.5 $\mathrm{N}$ force is needed in order to rupture the BP even if it has a $15 \mathrm{~mm}$ rip on it. On the other hand, NBP can withstand $46.5 \mathrm{~N}$ force having a same kind of rip on it. From these testes it clearly can be understood that the BP has more tear strength that the NBP and this is an important factor. Because, if the BP doesn't have as much tear 
strength as the NBP then it cannot be used as the replacement of NBP. So the BP is a very competitive replacement of the NBP due to its higher tear strength.

\subsection{GSM Determination}

The weight of $100 \mathrm{~cm}^{2} \mathrm{BP}$ and NBP samples were measured by a electric balance and the results were $1.953 \mathrm{gm}$ and $1.901 \mathrm{gm}$. By using these results the GSM of both BP and NBP was calculated with the help of equation 4.

$$
\text { GSM }=\text { Weigth of } 100 \mathrm{~cm}^{2} \text { sample } \times 100
$$

Here,

$$
\begin{aligned}
& \text { Weight of the } 100 \mathrm{~cm}^{2} \text { sample of } \mathrm{BP}, \mathrm{W}_{1}=1.953 \mathrm{gm} \\
& \text { Weight of the } 100 \mathrm{~cm}^{2} \text { sample of NBP, } \mathrm{W}_{2}=1.901 \mathrm{gm} \\
& \text { So, GSM of BP }=\mathrm{W}_{1} \times 100=1.853 \times 100=195.3 \mathrm{gm} / \mathrm{m}^{2} \\
& \mathrm{GSM} \text { of NBP }=\mathrm{W}_{2} \times 100=1.801 \times 100=190.1 \mathrm{gm} / \mathrm{m}^{2}
\end{aligned}
$$

GSM of BP and NBP was determined as $195.3 \mathrm{gm} / \mathrm{m}^{2}$ and $190.1 \mathrm{gm} / \mathrm{m}^{2}$ respectively. The GSM of NBP was selected almost similar to the BP for comparative study. The test result of NBP ensures that the GSM of it was almost similar to the GSM of the BP. However, the GSM of the BP is slightly high in order to use it as the alternative of the regular polyethylene. So it is possible to use this BP where it will withstand against a large amount of frictional force.

\subsection{Stiffness Test}

Pneumatic stiffness testing system was used in order to determine the stiffness of the BP and NBP with a good precision. The stiffness of BP was determined as $28.8 \mathrm{~N}$ and the NBP had a stiffness of $8.4 \mathrm{~N}$. It means maximum $28.8 \mathrm{~N}$ force was needed in order to push the BP sample through the orifice and maximum $8.4 \mathrm{~N}$ force was needed in order to push the BP sample through the orifice of the steel platform. So it clearly indicates that the BP is lot stiffer than the NBP. This has both positive and negative impacts. As the BP is much stiffer, so it can be used as a hard plastic. It clearly can overcome high vertical forces when necessary. However, this BP is not suitable for much bending. NBP can be easily bended and folded, but this BP is not bendable and foldable like the NBP.

\subsection{Melting Point Determination}

Melting point of both BP and NBP were determined by using STUART SMF30 melting point determining machine. The melting point of BP was determined as $189.8^{\circ} \mathrm{C}$. On the other hand, the melting point of the NBP was determined as $122.2^{\circ} \mathrm{C}$. It can be clearly seen that the melting point of BP is much higher than the NBP. So it takes more heat to melt down the BP which is a positive sign. As the BP is intended to be used instead of regular plastics, so this high melting point of BP will help it to withstand more temperature than the regular plastics. Normal polyethylene generally melts down or deform under high temperature. However, this BP will able to survive any physical contact with a high temperature body even if the temperature is more than $170^{\circ} \mathrm{C}$. This BP is also capable of survive the direct heat of bright sun shine. While conducting the melting temperature 
determination test it is observed that the BP does not shrink under the high temperature. On the other hand, the NBP started to shrink at the temperature of $85.8^{\circ} \mathrm{C}$ before melting down at $122.2^{\circ} \mathrm{C}$. Permanent deformation occurs to the NBP due to this shrinking process. However, no noticeable shrinkage or deformation occurs to the BP before melting down, which gives an upper hand than the NBP.

\subsection{Microscopic Examination}

The morphology of the BP film was examined using a XSP L101 Biological microscope using the 300X zoom in order to confirm presence of starch on the surface of the film. From the figure 5, the presence of organic starch can clearly be seen at the surface of the BP film. The shape of the starches is granule shape and a there were a good number of them which could be seen from the figure 5. The flat and smooth surface of the film was around those granule shaped starches. The morphology which is presented in figure 5 confirms the presence of starch in the film which is one of the main elements of the BP. The general size of potato starch is 15-75 $\mu \mathrm{m}$. From the microscopic image the size of the potato starches were measured as approximately $30 \mu \mathrm{m}$ and $50 \mu \mathrm{m}$, which are within the standard size range. This microscopic test gives the visual assurance of the presence of starch in the BP film.

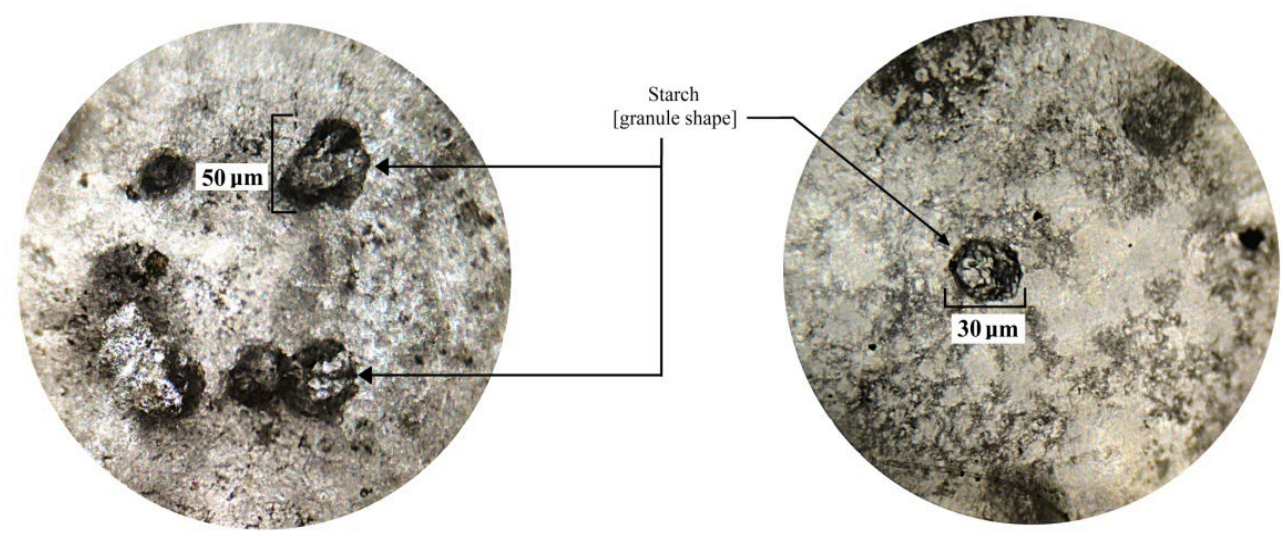

Figure 5: Morphological structure of BP film surface

\subsection{Fourier Transform Infrared (FTIR) Test}

FTIR test results for both BP and NBP are graphically represented in the Figure 6. These will help to understand about existing chemical groups and bonds in the testing materials. All the finding from the FTIR graphs have been systematically presented in the Table 2. Figure 6 (a) shows the FTIR result of NBP. FTIR absorbance bands of NBP at $3430 \mathrm{~cm}^{-1}$ indicated the presence of Hydroxyl group (OH) in the material. Symmetrical stretch of C-H was confirmed by the presence of absorbance bands at $3052 \mathrm{~cm}^{-1}$. FTIR absorbance bands at $2960 \mathrm{~cm}^{-1}$ and $2910 \mathrm{~cm}^{-1}$ indicated the presence of $\mathrm{C}-\mathrm{H}$ bond. Stretching of $\mathrm{C}=\mathrm{O}$ of carboxylic acid group in the material was confirmed by the FTIR absorbance band at $1732 \mathrm{~cm}^{-1}$. Vibrations aromatic skeleton with stretching $\mathrm{C}=\mathrm{C}$ was indicated by the absorbance band at $1505 \mathrm{~cm}^{-1}$. The FTIR absorbance band of NBP at $1345 \mathrm{~cm}^{-1}$ indicated the Stretching of the C-O group due to the deformation of the O-H group. The presence of Terephthalate Group $\left(\mathrm{OOCC}_{6} \mathrm{H}_{4}-\mathrm{COO}\right)$ was confirmed by the absorbance band at $1240 \mathrm{~cm}^{-1}$. The indication of the presence of Methylene group and vibrations of the ester $\mathrm{C}-\mathrm{O}$ bond was given by the FTIR absorbance bands 
at $1090 \mathrm{~cm}^{-1} \& 1055 \mathrm{~cm}^{-1}$. FTIR absorbance bands at $870 \mathrm{~cm}^{-1}$ indicated the presence of Aromatic rings $1,2,4,5$ in the NBP. Interaction of polar ester groups and benzene rings were determined by the FTIR absorbance band at $710 \mathrm{~cm}^{-1}$. So it can clearly be understood that NBP is mostly consisted of strong Hydro-Carbon bonds and the ethylene molecule is the basic element of this NBP. Carboxylic acid group, Terephthalate Group and Methylene group are also present in NBP which can be from the FTIR graph. That is why the polyethelene is mostly nonbiodegradable and it takes so much time to naturally break these strong bonds in order to degrade the material.

On the other hand, Figure 6 (b) shows the graphical representation of the FTIR curve of BP. FTIR absorbance band of BP at $3265 \mathrm{~cm}^{-1}$ indicated the complex vibrational stretches of Hydroxyl group (OH) in the material. Hydrogen atom stretches with the carbon on the methane ring was specified by the absorbance band at 2930 $\mathrm{cm}^{-1}$. The presence of acetone and amine groups was shown by the absorbance band at $1640 \mathrm{~cm}^{-1}$. Absorbance band at $1303 \mathrm{~cm}^{-1}$ had contributed to the presence of ester sulphate group in the BP. FTIR absorbance bands of $\mathrm{BP}$ at $1145 \mathrm{~cm}^{-1}, 1080 \mathrm{~cm}^{-1}, 980 \mathrm{~cm}^{-1} \& 922 \mathrm{~cm}^{-1}$ indicated the presence of $\mathrm{C}-\mathrm{O}$ bond in the material. C-O is very common the structure of starch because 1-4 glycosidic linkage or bond is used to join alpha D-glucose molecules together. So this clearly indicates the mass presence of starch in the BP. C-H bending in the material is indicated by the absorbance band of BP at $860 \mathrm{~cm}^{-1}$. All these evidences indicate that the BP is made of organic materials mostly with starch which are biodegradable materials.

Table 2: Bands with assigned vibration modes from FTIR spectrum of the BP and NBP sample

\begin{tabular}{|c|c|c|c|}
\hline \multicolumn{2}{|r|}{$\mathbf{B P}$} & \multicolumn{2}{|r|}{ NBP } \\
\hline $\begin{array}{l}\text { Absorption bands } \\
\qquad\left(\mathrm{cm}^{-1}\right)\end{array}$ & Bands & $\begin{array}{l}\text { Absorption bands } \\
\left(\mathrm{cm}^{-1}\right)\end{array}$ & Bands \\
\hline 3265 & $\begin{array}{l}\text { complex vibrational stretches of } \\
\text { OH group [17] }\end{array}$ & 3430 & OH group (hydroxyl) [19] \\
\hline 2930 & $\begin{array}{l}\text { hydrogen atom stretches with } \\
\text { the carbon on the methane ring } \\
{[\mathbf{1 7 , 1 8}]}\end{array}$ & 3052 & Symmetrical stretch of CH [20] \\
\hline 1640 & acetone and amine groups [18] & 2960 and 2910 & Presence of C-H bond $[\mathbf{1 9 , 2 0 ]}$ \\
\hline 1303 & ester sulphate $[\mathbf{1 7 , 1 8}]$ & 1732 & $\begin{array}{l}\text { Stretching of } \mathrm{C}=\mathrm{O} \text { of carboxylic } \\
\text { acid group [20] }\end{array}$ \\
\hline $1145,1080,980,922$ & $\mathrm{C}-\mathrm{O}$ bond $[\mathbf{1 7 , 1 8}]$ & 1505 & $\begin{array}{l}\text { Vibrations aromatic skeleton } \\
\text { with stretching } C=C[\mathbf{2 0}]\end{array}$ \\
\hline 860 & C-H bending [17] & 1345 & $\begin{array}{l}\text { Stretching of the C-O group } \\
\text { deformation of the O-H group } \\
{[\mathbf{1 9 , 2 0 ]}}\end{array}$ \\
\hline & & 1240 & $\begin{array}{l}\text { Terephthalate Group }\left(\mathrm{OOCC}_{6}\right. \\
\left.\mathrm{H}_{4}-\mathrm{COO}\right)[\mathbf{2 0}]\end{array}$ \\
\hline & & $1090-1055$ & $\begin{array}{l}\text { Methylene group and vibrations } \\
\text { of the ester } \mathrm{C}-\mathrm{O} \text { bond }[\mathbf{1 9 , 2 0 ]}\end{array}$ \\
\hline & & 870 & Aromatic rings $1,2,4,5[\mathbf{2 0}]$ \\
\hline & & 710 & $\begin{array}{l}\text { Interaction of polar ester groups } \\
\text { and benzene rings [20] }\end{array}$ \\
\hline
\end{tabular}




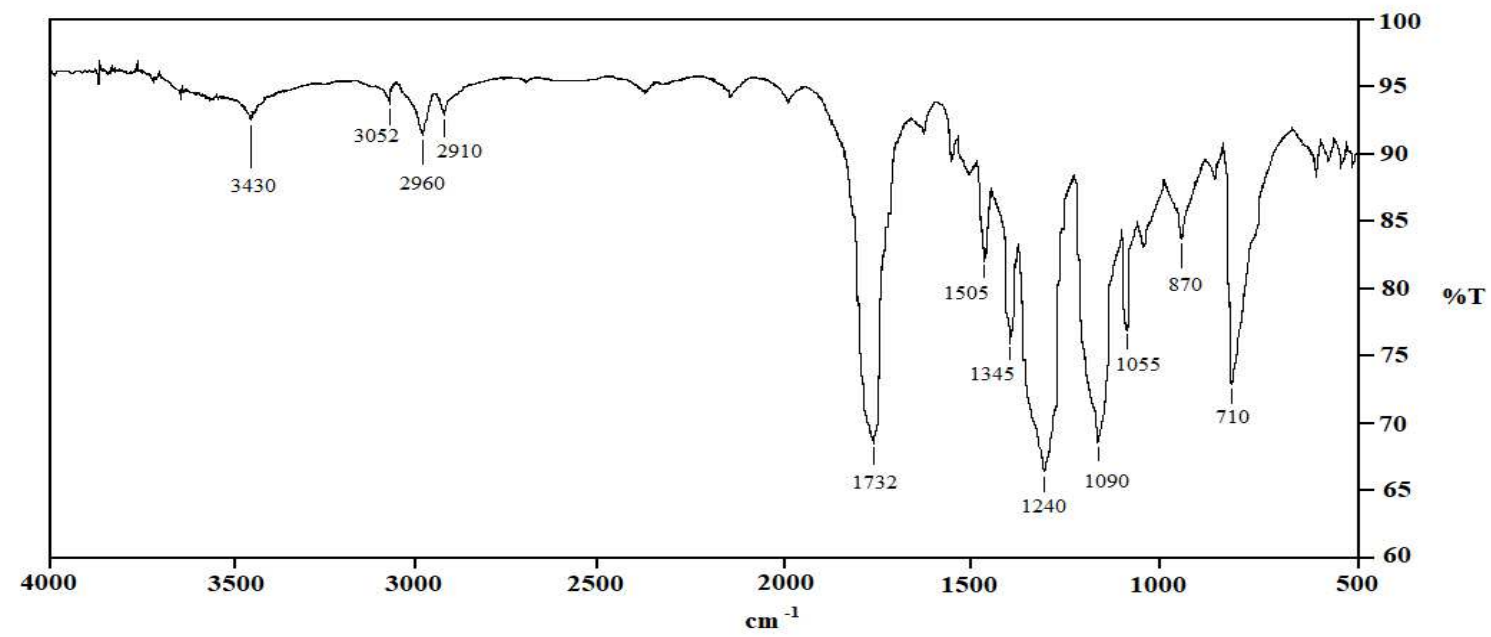

(a)

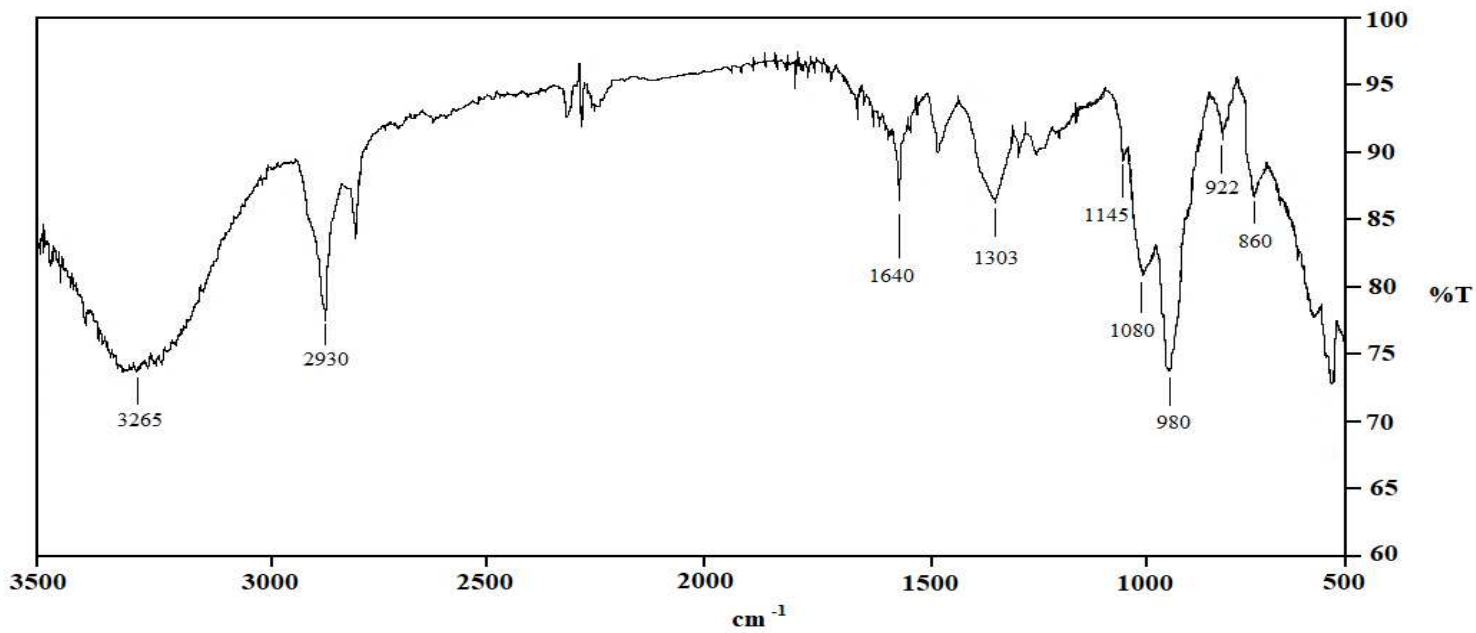

(b)

Figure 6: FTIR graph of (a) NBP and (b) BP

\subsection{Water Vapor Transmission Test}

In order to determine the water vapor transmission rate, the total weight before the test for both BP and NBP was needed to be determined. The calculations are given below:

Weight of the pot including the permeability cup $=150.734 \mathrm{gm}$

Weight of the $0.4 \mathrm{ft}^{2} \mathrm{BP}$ sample, $\mathrm{W}_{1}=7.260 \mathrm{gm}$

Weight of the $0.4 \mathrm{ft}^{2} \mathrm{NBP}$ sample, $\mathrm{W}_{2}=7.06 \mathrm{gm}$

Weight of the $100 \mathrm{ml}$ water $=100 \mathrm{gm}$

Therefore,

Total weight of the pot including BP sample before testing, $\mathrm{W}_{3}=150.734+7.260+100=257.994 \mathrm{gm}$

Total weight of the pot including NBP sample before testing, $\mathrm{W}_{4}=150.734+7.06+100=257.794 \mathrm{gm}$ 
After the tests were individually done for both BP and NBP samples, the total weights were again measured by using electric balance. The total weights were determined as below:

Total weight of the pot including BP sample after testing, $\mathrm{W}_{5}=257.622 \mathrm{gm}$

Total weight of the pot including NBP sample after testing, $\mathrm{W}_{6}=257.789 \mathrm{gm}$

Both of the tests were run for 30 minutes. So time, $\mathrm{T}=0.5 \mathrm{hr}$ and the area of both samples were, $\mathrm{A}=0.4 \mathrm{ft}^{2}$.

So,

Water vapor transmission rate of BP sample $=\frac{W_{3}-W_{5}}{T \times A}=\frac{257.994-257.622}{0.5 \times 0.4}=1.86 \mathrm{gm} / \mathrm{hr} . \mathrm{ft}^{2}$

Water vapor transmission rate of NBP sample $=\frac{W_{4}-W_{6}}{T \times A}=\frac{257.794-257.789}{0.5 \times 0.4}=0.0225 \mathrm{gm} / \mathrm{hr} . \mathrm{ft}^{2}$

From the result calculation it is found that the water vapor transmission rate for BP and NBP are $1.86 \mathrm{gm} / \mathrm{hr} . \mathrm{ft}^{2}$ and $0.0225 \mathrm{gm} / \mathrm{hr} . \mathrm{ft}^{2}$ respectively. It can be concluded that he normal polyethylene has a very poor water vapor transmission rate due to its compact structure. On the other hand, the BP has less compact structure than the normal polyethylene due to the presence of Starch polymer. This less compact structure gives the BP more water vapor transmission rate than the polyethylene. This property of BP can be utilized in the packaging and storing facility. Sometime, food can be rotten due to excessive moisture in the container bag. If the water vapor cannot escape the packaging then it can cause food rotting. In this case the BP can be a good alternative of polyethylene bags.

\subsection{Biodegradability Test}

Result of biodegradability test for the BP is shown in the table 3.

Table 3: Comparison between biodegradable material and polythene

\begin{tabular}{|c|c|c|c|c|c|c|c|c|}
\hline \multirow{2}{*}{$\begin{array}{c}\text { Isolates } \\
\text { Code }\end{array}$} & \multicolumn{4}{|c|}{ Polythene } & \multicolumn{4}{|c|}{ Biodegradable material } \\
\cline { 2 - 10 } & $\begin{array}{c}\text { Initial } \\
\text { weight } \\
(\mathrm{gm})\end{array}$ & $\begin{array}{c}\text { Final } \\
\text { weight } \\
(\mathrm{gm})\end{array}$ & Difference & $\%$ & $\begin{array}{c}\text { Initial } \\
\text { weight } \\
(\mathrm{gm})\end{array}$ & $\begin{array}{c}\text { Final } \\
\text { weight } \\
(\mathrm{gm})\end{array}$ & Difference & $\%$ \\
\hline PDB-1 & 0.0115 & 0.0111 & 0.0004 & 3.47 & 0.137 & 0.1065 & 0.305 & 22.26 \\
\hline PDB-2 & 0.0105 & 0.0103 & 0.0002 & 1.9 & 0.151 & 0.1235 & 0.0275 & 18.21 \\
\hline PDB-3 & 0.0124 & 0.0123 & 0.0001 & 0.81 & 0.163 & 0.1521 & 0.0109 & 6.69 \\
\hline PDB-4 & 0.0122 & 0.0118 & 0.0004 & 3.28 & 0.157 & 0.1394 & 0.0176 & 11.21 \\
\hline
\end{tabular}

Sample Size: Polythene was cut into $1 \mathrm{x} 1 \mathrm{~cm}$ so does the experimental material.

Bacterial Source: Soil Sample

Total Bacteria Isolated: $10 \quad$ Total Bacteria used: 4

Polythene Degradable Bacteria: PDB-1, PDB-2, PDB-3, PDB-4. 


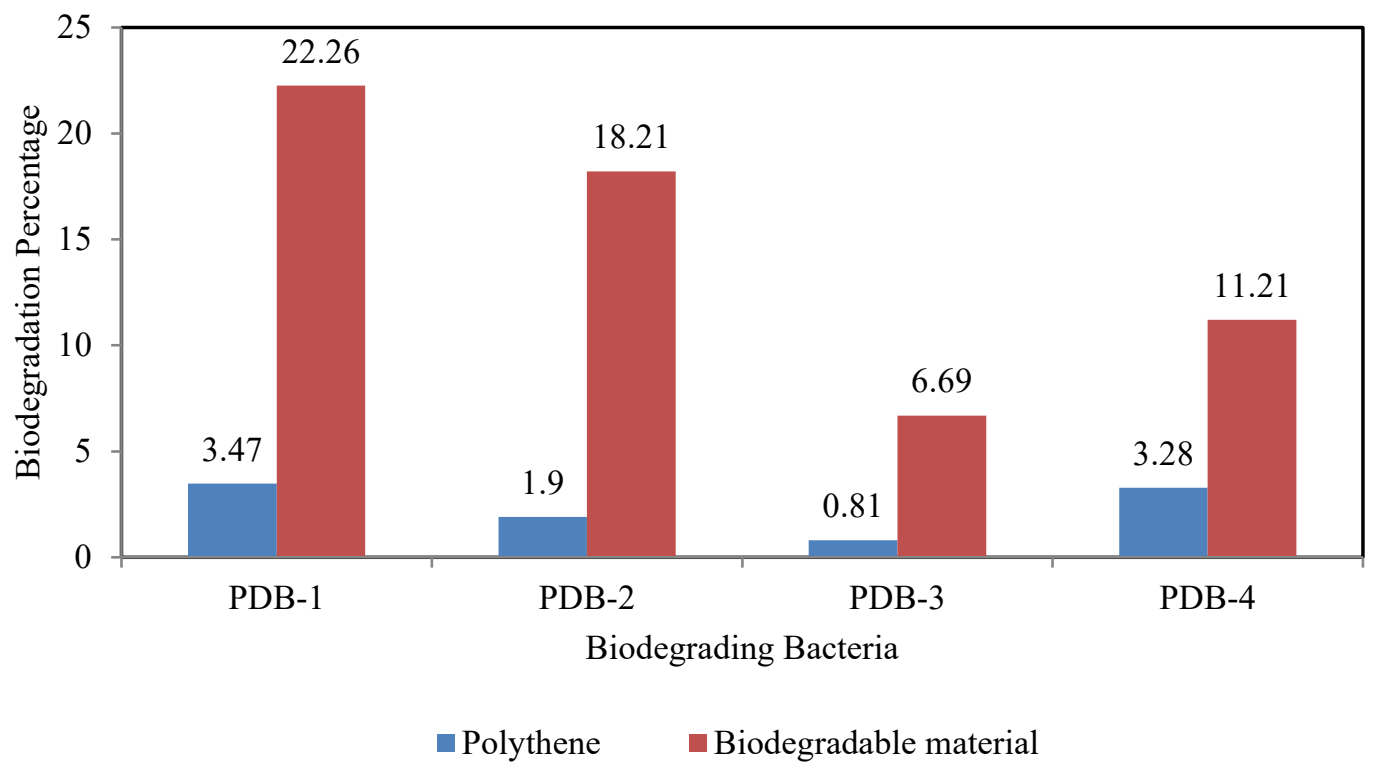

Figure 7: Biodegradation percentage graph of (a) NBP and (b) BP

From the test results which is shown in the figure 7, it can be seen that the normal plastic is only $3.47 \%, 1.9 \%$, $0.81 \%$ and $3.28 \%$ by using the PDB-1, PDB-2, PDB-3 and PDB-4 respectively. On the other hand the newly developed plastic showed excellent biodegradability percentage. Newly developed starch based plastic had a biodegradability percent of $22.86 \%, 18.21 \%, 6.69 \%$ and $11.21 \%$ by using the PDB-1, PDB-2, PDB-3 and PDB4 respectively. The duration of the test was 10 days and that means the starch based plastic degraded almost $23 \%$ within 10 days only. This shows the starch based plastic has a very excellent biodegradability property with respect to the normal polyethylene.

\subsection{CONCLUSION}

Starch based plastic material has shown a very promising starts which can be seen in this research paper. Head to head against the normal plastic, it has shown its resiliency and it is very likely to be the alternative of the nonbiodegradable plastic. The high tensile strength and tear strength of the starch based biodegradable plastic indicates its mechanical compactness and ability to withstand the external forces. However the GSM of the biodegradable plastic (195 GSM) is much higher in compare to the regular plastic which has increased the stiffness of the plastic as well. This can be described as a possible lacking of this research work. The film formation process was conducted without any sophisticated machineries where as the normal plastics can easily achieve very low GSM by using the modern machineries. There is still a scope to reduce the GSM of the plastic by doing further research. However, this high GSM plastic can also be used where it needs to face high mechanical abrasion. It also has a high melting point of around $190^{\circ} \mathrm{C}$ as well. So this starch based plastics can be used as bags, covering material, packaging, food containers, compostable waste collection bags, crockery, cutlery, bottles, tea bags, jars and air pillow etc. In this research the biodegradation ability of the newly developed plastic is highly emphasized and keeping that fact in the head, all the process and parameters are 
being set. The biodegradation test showed a very promising result as almost $23 \%$ of the plastic got degraded within only 10 days. So this research work can be considered as a great achievement in the case of finding a new biodegradable plastic. However more research is need to be conducted in order to develop and introduce new properties of the biodegradable plastic to versatile its uses.

\section{References}

[1] Nickles, S. (1996). American Plastic: A Cultural History. By Jeffrey L. Meikle · New Brunswick, N.J.: Rutgers University Press, 1995. 500 pp. Illustrations, Bibliography and Index. \$49.95. ISBN 0-8135-2234x. Business History Review, 70(4), 600-602. doi: 10.2307/3117321

[2] Huang, J., Shetty, A., \& Wang, M. (1990). Biodegradable plastics: A review. Advances In Polymer Technology, 10(1), 23-30. doi: 10.1002/adv.1990.060100103

[3] Pintér, Á., Sud, A., Sureshkumar, D., \& Klussmann, M. (2010). Autoxidative Carbon-Carbon Bond Formation from Carbon-Hydrogen Bonds. Angewandte Chemie International Edition, 49(29), 5004-5007. doi: 10.1002/anie.201000711

[4] Flieger, M., Kantorová, M., Prell, A., Řezanka, T., \& Votruba, J. (2003). Biodegradable plastics from renewable sources. Folia Microbiologica, 48(1), 27-44. doi: 10.1007/bf02931273

[5] Ilyas, R., Sapuan, S., Ishak, M., \& Zainudin, E. (2018). Development and characterization of sugar palm nanocrystalline cellulose reinforced sugar palm starch bionanocomposites. Carbohydrate Polymers, 202, 186202. doi: 10.1016/j.carbpol.2018.09.002

[6] Jung, K., Müller, M., \& Schmidt, R. (2000). Intramolecular O-Glycoside Bond Formation. Chemical Reviews, 100(12), 4423-4442. doi: 10.1021/cr990307k

[7] Chen, C., Zhao, X., Yen, H., Ho, S., Cheng, C., \& Lee, D. et al. (2013). Microalgae-based carbohydrates for biofuel production. Biochemical Engineering Journal, 78, 1-10. doi: 10.1016/j.bej.2013.03.006

[8] McGlashan, S., \& Halley, P. (2003). Preparation and characterisation of biodegradable starch-based nanocomposite materials. Polymer International, 52(11), 1767-1773. doi: 10.1002/pi.1287

[9] Ren, X. (2003). Biodegradable plastics: a solution or a challenge?. Journal Of Cleaner Production, 11(1), 27-40. doi: 10.1016/s0959-6526(02)00020-3

[10] Otaigbe, J., Goel, H., Babcock, T., \& Jane, J. (1999). Processability and Properties of Biodegradable Plastics Made from Agricultural Biopolymers. Journal Of Elastomers \& Plastics, 31(1), 56-71. doi: $10.1177 / 009524439903100104$

[11] Bergel, B., Dias Osorio, S., da Luz, L., \& Santana, R. (2018). Effects of hydrophobized starches on thermoplastic starch foams made from potato starch. Carbohydrate Polymers, 200, 106-114. doi: 10.1016/j.carbpol.2018.07.047

[12] Lim, J., Hii, S., Chee, S., \& Wong, C. (2018). Sargassum siliquosum J. Agardh extract as potential material for synthesis of bioplastic film. Journal Of Applied Phycology, 30(6), 3285-3297. doi: 10.1007/s10811-018$1603-2$ 
[13] Lodha, P., \& Netravali, A. (2005). Thermal and mechanical properties of environment-friendly 'green' plastics from stearic acid modified-soy protein isolate. Industrial Crops And Products, 21(1), 49-64. doi: 10.1016/j.indcrop.2003.12.006

[14] Gupta, A., Sharma, M., \& Kumar, V. (2008). Preparation and Characterization of Potato Starch Based Low Density Polyethylene/Low Density Polyethylene Grafted Maleic Anhydride Biodegradable Polymer Composite. Polymer-Plastics Technology And Engineering, 47(9), 953-959. doi: 10.1080/03602550802274597

[15] Fabunmi, O., Tabil, L., Panigrahi, S., \& Chang, P. (2011). Effects of Incorporating Polycaprolactone and Flax Fiber into Glycerol-Plasticized Pea Starch. Journal Of Polymers And The Environment, 19(4), 841-848. doi: $10.1007 /$ s10924-011-0374-5

[16] Hossain, K., Das, S., Kundu, S., Afrin, S., Nurunnabi, T., \& Rahman, S. (2019). ISOLATION AND CHARACTERIZATION OF POLYTHENE DEGRADING BACTERIA FROM GARBAGE SOIL. International Journal Of Agriculture Environment And Bioresearch,04(05), 254-263. doi: 10.35410/ijaeb.2019.4444

[17] Pereira, A., Silva, M., Lima Júnior, É., Paula, A., \& Tommasini, F. (2017). Processing and Characterization of PET Composites Reinforced With Geopolymer Concrete Waste. Materials Research, 20(suppl 2), 411-420. doi: 10.1590/1980-5373-mr-2017-0734

[18] Ioakeimidis, C., Fotopoulou, K., Karapanagioti, H., Geraga, M., Zeri, C., \& Papathanassiou, E. et al. (2016). The degradation potential of PET bottles in the marine environment: An ATR-FTIR based approach. Scientific Reports, 6(1). doi: 10.1038/srep23501

[19] Ruggero, F., Carretti, E., Gori, R., Lotti, T., \& Lubello, C. (2020). Monitoring of degradation of starchbased biopolymer film under different composting conditions, using TGA, FTIR and SEM analysis. Chemosphere, 246, 125770. doi: 10.1016/j.chemosphere.2019.125770

[20] Warren, F., Gidley, M., \& Flanagan, B. (2016). Infrared spectroscopy as a tool to characterise starch ordered structure - a joint FTIR-ATR, NMR, XRD and DSC study. Carbohydrate Polymers, 139, 35-42. doi: 10.1016/j.carbpol.2015.11.066 